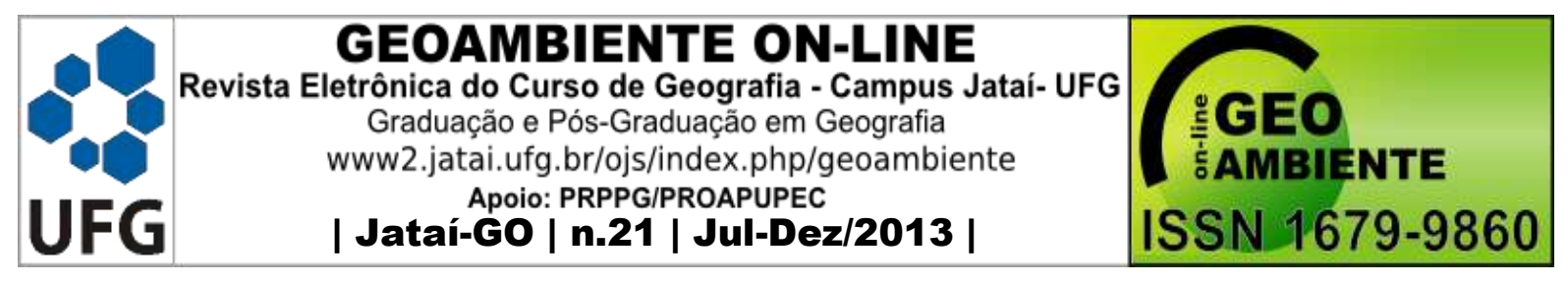

\title{
DIAGNÓSTICO DA DENGUE NO MUNICÍPIO DE PIRAPORA (MG), NOS ANOS DE 2010 À 2011: ASSOCIAÇÃO ENTRE CASOS NOTIFICADOS E VARIÁVEIS CLIMÁTICAS
}

\author{
João Paulo Gomes da Silva,Vanda Aparecida Costa \\ Universidade Federal de Uberlândia, Mestrando (a) em Geografia, jpgomesgeo@gmail.com; \\ vandageografia@msn.com)
}

\section{RESUMO}

O presente trabalho tem por objetivo apresentar os casos e notificações da dengue na cidade de Pirapora-MG, entre anos de 2010 e 2011 e, realizar uma análise dos fatores climáticos envolvidos. No Brasil a incidência de dengue tem um perfil sazonal, com valores maiores nos primeiros meses do ano, no verão e outono, uma vez que há um aumento na umidade e na temperatura, fatores que favorecem a proliferação do Aedes aegypti. A disseminação da dengue na cidade de Pirapora acontece principalmente no verão, sendo os meses de dezembro, janeiro e fevereiro mais críticos, pois, são nestes períodos que são registrados as maiores índice de chuva, elevadas taxas relativas da umidade do ar e temperaturas altas. Após o período analisado (anos de 2010 e 2011) percebeu-se uma clara diminuição do número de casos de dengue, redução que pode ser explicada dentre outros fatores, pela execução de medidas de combate ao vetor, à variação dos índices de umidade no município além do ciclo natural de imunização dos organismos em relação ao vírus circulante.

PALAVRAS-CHAVE: Dengue, Aedes aegypti, Clima, Pirapora (MG).

\section{ABSTRACT \\ DIAGNOSIS OF DENGUE IN THE COUNTY OF PIRAPORA (MG), IN THE YEARS 2010 TO 2011: ASSOCIATION BETWEEN CASES NOTIFIED AND CLIMATE VARIABLES}

This paper intends to present cases and reports of dengue in the city of Pirapora-MG, between years 2010 and 2011, and conduct an analysis of climatic factors involved. In Brazil the

\footnotetext{
Artigo recebido para publicação em 09 de Janeiro de 2013

Artigo aprovado para publicação em 20 de Dezembro de 2013
} 


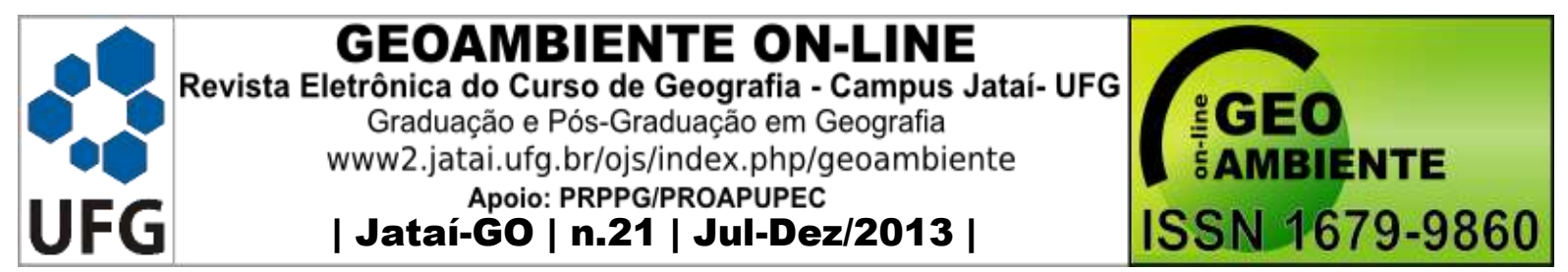

incidence of dengue has a seasonal profile, with higher values in the early months of the year, in summer and fall, since there is an increase in humidity and temperature, factors that favor the proliferation of Aedes aegypti. The spread of dengue in the city of Pirapora happens mainly in the summer, with the months of December, January and February most critical, because these are periods which are recorded the highest rain rate, high rates of relative humidity and high temperatures. In the analyzed period (2010 and 2011) saw a clear decrease in the number of dengue cases, reduction can be explained among other factors, the implementation of measures to combat the vector, the variation in humidity in the city beyond immunization of the natural cycle of organisms in relation to circulating virus.

KEY WORDS: Dengue, Aedes aegypti, Climate, Pirapora (MG).

\section{RESUMEN}

\section{DIAGNÓSTICO DE DENGUE EN EL MUNICIPIO DE PIRAPORA (MG) EN LOS} AÑOS 2010 A 2011: LA ASOCIACIÓN ENTRE LOS CASOS REPORTADOS Y LAS VARIABLES CLIMÁTICAS

Este trabajo tiene como objetivo presentar los casos y los informes de dengue en la ciudad de Pirapora-MG, entre los años 2010 y 2011, y llevar a cabo un análisis de los factores climáticos en cuestión. En Brasil, la incidencia de dengue tiene un perfil estacional, con valores más altos en los primeros meses del año, en verano y otoño, ya que hay un aumento de la humedad y la temperatura, factores que favorecen la proliferación del mosquito Aedes aegypti. La propagación del dengue en la ciudad de Pirapora ocurre principalmente en el verano, con los meses de diciembre, enero y febrero, más crítico, debido a que estos son periodos que se registran el mayor índice de lluvias, altos índices de humedad relativa y altas temperaturas. En el periodo analizado (2010 y 2011) se produjo un descenso claro del número de casos de dengue, la reducción se explica, entre otros factores, la aplicación de medidas de lucha contra el vector, la variación de la humedad en la ciudad más allá inmunización del ciclo natural de los organismos en relación con el virus circulante.

PALABRAS CLAVE: dengue, Aedes aegypti, Clima, Pirapora (MG).

\section{Introdução}

A dengue é uma arbovirose causada por um vírus da família Flaviviridae, que apresenta quatro sorotipos conhecidos: DENV-1, DENV-2, DENV-3 e DENV-4. Nas 


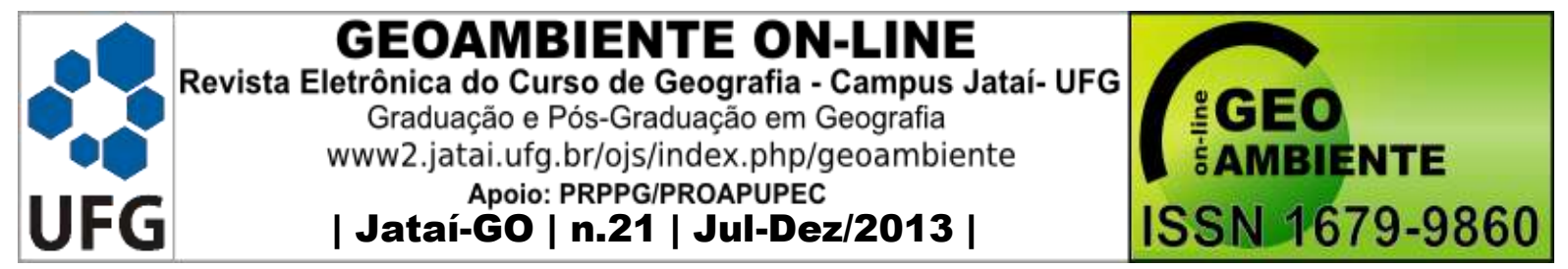

Américas a transmissão desse vírus para o homem se dá pelo mosquito da espécie Aedes aegypti, na Ásia, no entanto, sabe-se que a doença é mantida através da transmissão pelo mosquito da espécie Aedes albopictus.

Essa doença apresenta ampla distribuição mundial, principalmente em regiões tropicais e subtropicais, e a sua ressurgência pode ser atribuída a fatores associados às novas dinâmicas mundiais, como o aumento da produção de materiais descartáveis, que fornecem ambientes ideais para a reprodução do vetor. Além disso, o aumento da população mundial, associado à falta de planejamento urbano e à falta de infraestrutura adequada na área de saúde pública contribui para a transmissão da doença.

No Brasil a incidência de dengue tem um perfil sazonal, com valores maiores nos primeiros meses do ano, no verão e outono, uma vez que há um aumento na umidade e na temperatura, fatores que favorecem a proliferação do Aedes aegypti (Teixeira et al., 1999). O informe epidemiológico da dengue publicado pela Secretaria de Vigilância em Saúde no ano de 2010 aponta Minas Gerais como um dos estados que devem intensificar o monitoramento.

Dentre as dificuldades em conter a expansão da dengue no Brasil está a incapacidade em produzir vacinas, sendo assim, o controle da doença depende exclusivamente da redução da população do vetor, que se viabiliza a partir do envolvimento não só dos órgãos gestores, mas também de toda a comunidade. As medidas de controle envolvem eliminação de larvas, diminuição de recipientes propícios para a oviposição e o uso de inseticidas. No entanto, essas estratégias não têm sido realmente efetivas para o controle da doença (Barreto \& Teixeira, 2008). Portanto, é necessário conhecer o perfil de distribuição da dengue para a realização de um planejamento e adoção de novas medidas que sejam mais eficazes no controle do Aedes aegypti.

Na cidade de Pirapora - Norte de Minas Gerais percebe-se grandes esforços dos secretários de saúde em combater o mosquito Aedes aegypti com realização de campanhas e diversos outros procedimentos que inibe a presença desses vetores. Neste sentido, o presente trabalho teve por objetivo apresentar os casos e notificações da dengue na cidade de PiraporaMG, entre anos de 2010 e 2011 e, realizar uma análise dos fatores climáticos envolvidos.

Para compreendermos como se deu e quais os fatores propulsores ou inibidores da incidência da dengue, trabalhou-se com dados de temperatura, precipitação e umidade relativa do ar, no período de 2010 à 2011. Para que alcançar objetivo proposto, utilizou-se como metodologia: revisão bibliográfica, recorte histórico de jornais e consultas aos órgãos do 


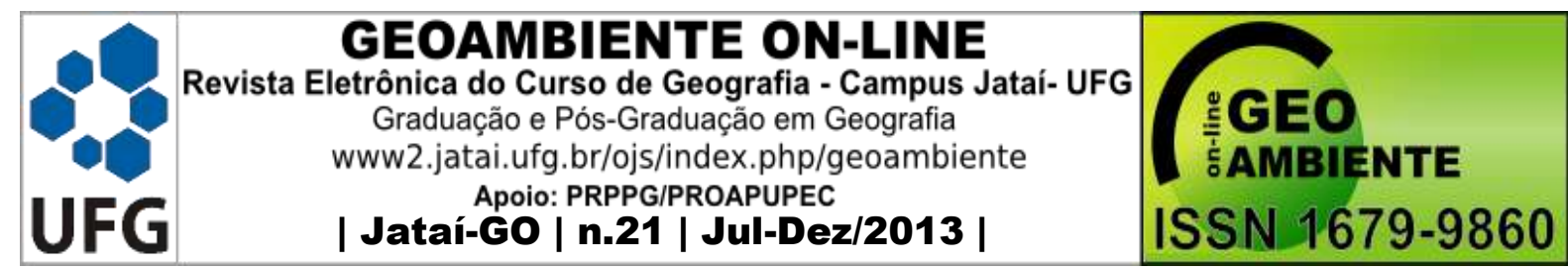

Sistema de Informação a Saúde Básica - SIAB/DATASUS, Instituto Nacional de Meteorologia e Instituto Brasileiro de Geografia e Estatística - IBGE. Utilizou-se também os dados e entrevistas dos secretários de saúde de Pirapora-MG concedida a Agencia Minas. A partir dessas informações procurou-se compreender os casos de dengue ocorridos no município de Pirapora em 2010 e 2011, e sua relação com as características climáticas locais.

\section{Materiais e Métodos}

De modo a atingir os objetivos traçados para a pesquisa realizou-se, inicialmente, uma série de consultas bibliográficas visando a construção de uma base teórica sobre a qual foram baseadas as discussões conceituais e análises do estudo de caso. Realizou-se pesquisas tanto em fontes secundárias (livros, dissertações, artigos científicos, etc.) quanto em fontes primárias (série histórica de dados climáticos do INMET -Instituto Nacional de Meteorologia, dados de casos notificados de dengue no Município de Pirapora - MG disponibilizados no SIAB - Sistema de Informação da Atenção Básica, além de informações e dados da Secretaria de Estado da Saúde de Minas Gerais, etc.).

A partir dos levantamentos teóricos, estatísticos, realizou-se a sistematização dos dados e informações e também a elaboração de material iconográfico, dentre os quais, mapeamento e a organização de tabelas, quadros e gráficos, que contribuirão na exposição dos resultados obtidos. Por fim, seguiu-se com a redação e revisão do texto final.

\section{Análise crítica - Casos de Dengue no Brasil e em Minas Gerais}

A dengue é uma doença com característica sazonal, ou seja, se concentra em um mesmo período, todos os anos e tem uma relação intrínseca com as condições climáticas locais. No Brasil, o período de maior incidência da dengue coincide com o verão, devido a maior ocorrência de chuvas e ao aumento da temperatura (MENDONÇA \& DANNI OLIVEIRA, 2007). De acordo com dados do Ministério da Saúde, aproximadamente 70\% dos casos de dengue ocorrem entre os meses de janeiro à maio, com exceção das regiões Norte e Nordeste, nas quais a temporada de chuvas começa tardiamente (em março e se estendem até julho). Apesar disso, a maior parte do território brasileiro apresenta condições favoráveis à reprodução do mosquito durante o ano todo, principalmente nos grandes centros urbanos com carência de saneamento básico. 


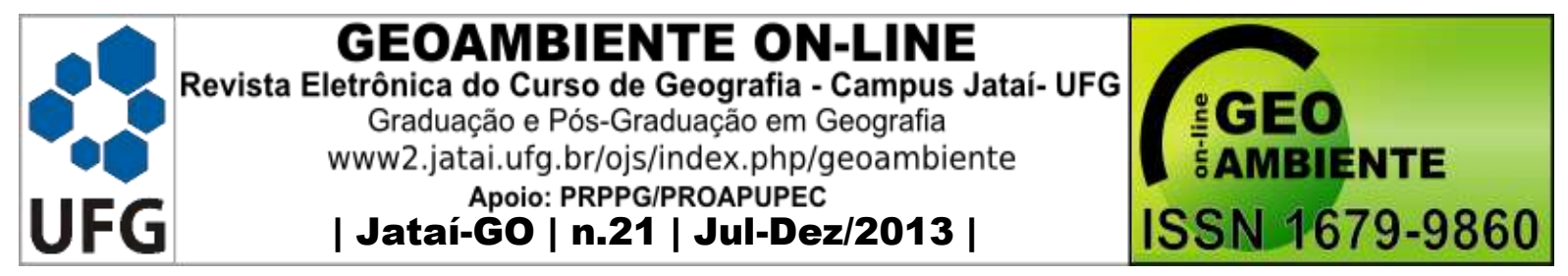

incidência, reflexo da ampla dispersão do Aedes aegypti no território nacional (BRASIL, 2010).

A presença do vetor, associada à mobilidade da população, levou à disseminação dos sorotipos DENV1 e DENV2 para 20 dos 27 estados do país. Entre os anos de 1990 e 2000, várias epidemias foram registradas, sobretudo nos grandes centros urbanos das regiões Sudeste e Nordeste do Brasil, responsáveis pela maior parte dos casos notificados. As regiões Centro-Oeste e Norte foram acometidas mais tardiamente, com epidemias registradas a partir da segunda metade da década de 90 (BRASIL, 2009).

De acordo com as Diretrizes Nacionais para a prevenção e Controle de epidemias de dengue:

A circulação do sorotipo DENV3 do vírus foi identificada, pela primeira vez, em dezembro de 2000, no Estado do Rio de Janeiro e, posteriormente, no Estado de Roraima, em novembro de 2001. Em 2002, foi observada a maior incidência da doença, quando foram confirmados cerca de 697.000 casos, refletindo a introdução do sorotipo DENV3. Essa epidemia levou a uma rápida dispersão do sorotipo DENV3 para outros estados, sendo que, em 2004, 23 dos 27 estados do país já apresentavam a circulação simultânea dos sorotipos DENV1, DENV2 e DENV3 do vírus da dengue (BRASIL, 2009, p. $11)$.

Nos últimos vinte anos o Brasil vivenciou quatro grandes epidemias: 1998, 2002, 2008 e 2010. Todas estiveram ligadas à mudança do sorotipo predominante. Em julho de 2010, o estado de Roraima notificou o primeiro caso de dengue tipo IV, 28 anos após o vírus ter circulado no Brasil.

Vários são os fatores que explicam a expansão da doença no Brasil nos últimos anos. A aglomeração de pessoas sem imunidade ao vírus aumenta o risco de epidemias. De acordo com dados da PNAD - Pesquisa Nacional Por Amostra de Domicílios de 2009, cerca de 80\% da população brasileira vive em áreas urbanas. Outro fator explicativo seria a própria evolução populacional do Brasil: a população dobrou entre 1970 e 2000 . O problema crônico da falta de saneamento básico no Brasil facilita a ocorrência de doenças, dentre elas a dengue. Os Dados da PNAD/IBGE apontam que aproximadamente $15 \%$ dos domicílios brasileiros 


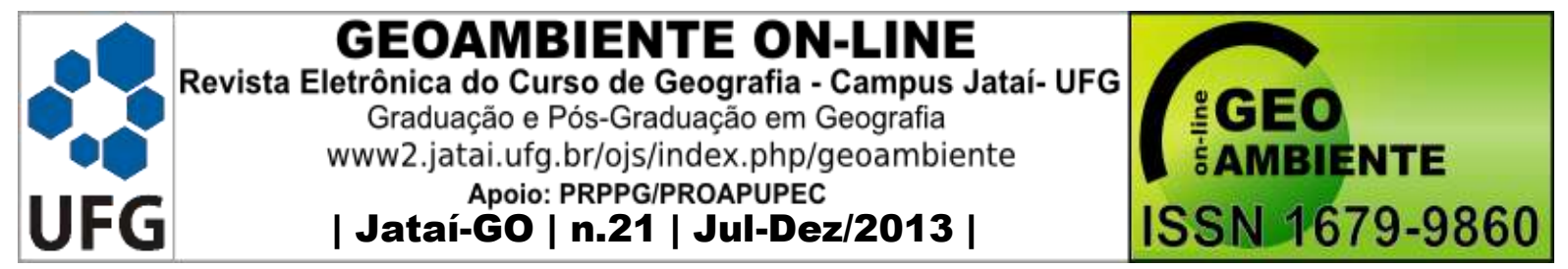

não contam com rede geral de abastecimento de água e mais de 10 milhões não contam com coleta regular de lixo.

Sendo assim, o atual quadro epidemiológico da dengue no país caracteriza-se pela ampla dispersão do Aedes Aegypti em todas as regiões brasileiras, com uma complexa dinâmica de distribuição do seu vírus, e circulação simultânea de três sorotipos virais (DENV1, DENV2 e DENV3) além da vulnerabilidade para a introdução do sorotipo DENV4.

A partir do ano de 2010 o quadro epidemiológico da dengue no Brasil sofre uma drástica transformação com sucessivas quedas do número de casos da doença. De acordo com o Boletim epidemiológico divulgado pelo Ministério da Saúde, em novembro de 2012, o número de casos graves de dengue caiu 64\% em 2012 em comparação ao ano anterior. A queda foi muito maior se forem considerados os números de 2010 - percentual de redução de 78\%. Enquanto de janeiro ao início de novembro em 2010, os casos graves da doença chegaram a 17.037, no mesmo período de 2012, o número caiu para 3.774. A tendência de queda já havia sido percebida em 2011 quando foram registrados 10.507 casos graves.

De acordo com dados do Ministério da Saúde de 2010, dos 26 estados brasileiros, 23 mais o Distrito Federal apresentaram reduções importantes de casos graves em 2012, com exceção de Alagoas, Mato Grosso e Goiás, onde houve aumento. O estado que apresenta maior redução é o Amazonas com queda de $96 \%$ em relação ao mesmo período do ano passado, seguido pelo Acre (94\%), Roraima (94\%) Paraná, (93\%), São Paulo (83\%), Espírito Santo (78\%) e Rio de Janeiro (76\%). Em números absolutos, o estado do Rio de Janeiro foi o que apresentou a maior redução de casos graves, registrando 891 casos graves de janeiro ao início de novembro de 2012, contra 3.783 no mesmo período do ano passado.

A quantidade de óbitos por dengue, no Brasil, também apresentou queda de $63 \%$ em comparação com 2010. De janeiro até a primeira semana de novembro, foram confirmados 247 óbitos, sendo que no mesmo período de 2010 foram 672 óbitos. Se a comparação for feita com o ano passado, quando ocorreram 481 mortes, o percentual de queda é de $49 \%$. Seguindo a mesma tendência de redução de casos, 15 estados e o Distrito Federal apresentaram redução no número de óbitos. Destaque também para os estados do Amapá, Santa Catarina, Rio Grande do Sul e o Distrito Federal que não apresentaram nenhuma morte (Ministério da Saúde, 2012.).

De acordo com o Informe epidemiológico da dengue de 2010, publicação do Ministério da Saúde, o estado de Minas Gerais se destaca pelo total de 48.723 casos 


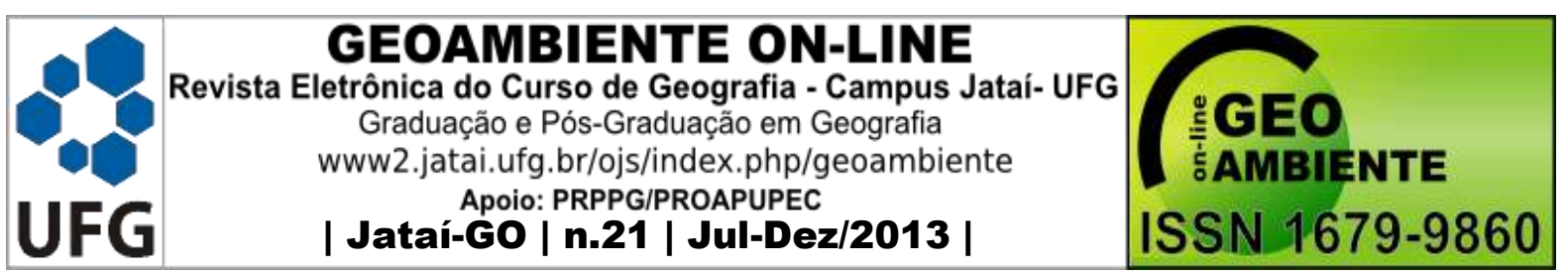

notificados, com incidência de 243,2 casos por 100 mil habitantes. Em Minas Gerais, 52,6\% se concentraram em 8 municípios, com destaque para Belo Horizonte (9.143; 18,8\%), Montes Claros $(4.424 ; 9,1 \%)$, Betim $(2.793 ; 5,7 \%)$, Carangola $(2.621 ; 5,4 \%)$, Arcos $(1.947 ; 4 \%)$, Pirapora $(1.646 ; 3,4 \%)$, Uberaba $(1.542 ; 3,2 \%)$ e Bom Despacho $(1.529 ; 3,1)$. Nas nove primeiras semanas de 2010, observou-se um aumento de 147,93\% dos casos notificados de dengue, passando de 19.652 casos em 2009 para 48.723 em 2010. Entretanto, acompanhando uma tendência nacional, desde 2010 o estado de Minas Gerais apresenta queda do número de casos graves de dengue, conforme demonstra a tabela 1.

De acordo com o secretário da Saúde de Minas Gerais, Antônio Jorge Souza Marques, em entrevista concedida à Rede Minas em 2012, “o Estado [de Minas Gerais] apresenta uma situação climática totalmente favorável ao mosquito, mas isso não pode ser usado como justificativa para $100 \%$ do problema, mesmo que o volume de água trazido pelas chuvas tenha representado, em algumas cidades, o maior volume de água dos últimos 100 anos. Tivemos um enorme êxito em 2011, se compararmos com 2010, em que houve uma redução de mais de $80 \%$ dos casos notificados. Porém, é fundamental que os gestores municipais tenham uma atenção especial e redobrem a atenção em 2012".

Tabela1: Casos confirmados e óbitos por Febre Hemorrágica do Dengue (FHD) e Dengue com Complicações (DCC), Minas Gerais, 2007- 2012.

\begin{tabular}{ccccc}
\hline Ano & $\begin{array}{c}\text { Casos de FHD } \\
\text { Confirmados }\end{array}$ & $\begin{array}{c}\text { Casos de DCC } \\
\text { Confirmados }\end{array}$ & $\begin{array}{c}\text { Casos por } \\
\text { Dengue Grave }\end{array}$ & $\begin{array}{c}\text { Óbitos por } \\
\text { Dengue Grave }\end{array}$ \\
\hline $\mathbf{2 0 0 7}$ & 9 & 71 & 80 & 7 \\
$\mathbf{2 0 0 8}$ & 62 & 197 & 259 & 16 \\
$\mathbf{2 0 0 9}$ & 132 & 418 & 550 & 24 \\
$\mathbf{2 0 1 0}$ & 175 & 1225 & 1400 & 106 \\
$\mathbf{2 0 1 1}$ & 165 & 39 & 204 & 22 \\
$\mathbf{2 0 1 2}$ & 13 & 56 & 69 & 10 \\
\hline
\end{tabular}

Fonte: SES/MG, 2012.

Org.: SILVA, J. P. G., 2012.

Dentre as ações efetivas para o controle da infestação da dengue em Minas Gerais em 2012, destaca-se a liberação de recursos do Sistema Estadual de Transporte em Saúde (Sets) da ordem de um milhão de reais, para a compra de aproximadamente 30 veículos do tipo picape, que irão auxiliar no transporte dos agentes e insumos, considerado pelos secretários municipais, como um dos grandes gargalos na promoção das ações de combate à dengue. 


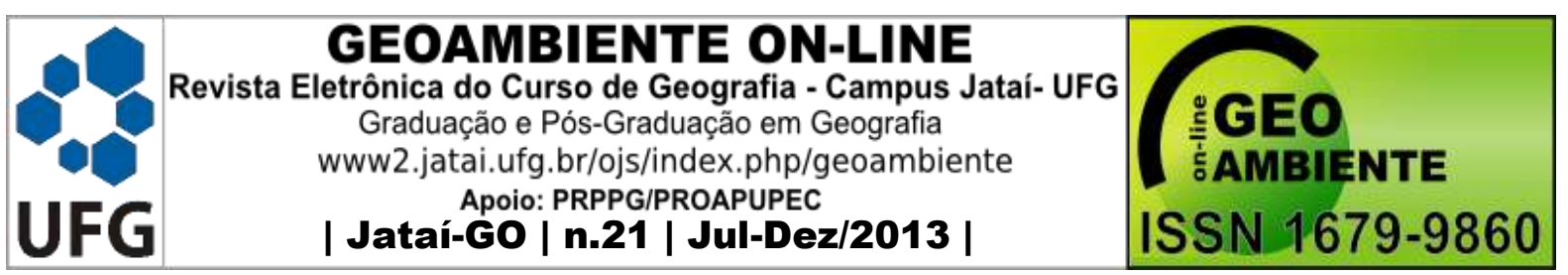

Além da liberação de recursos para compra de equipamentos, estava em andamento o treinamento de aproximadamente 50 médicos que, por meio das regionais de saúde, aperfeiçoaram e capacitaram à ação de profissionais locais para um eficaz diagnóstico da doença, uma vez que muitos dos casos que evoluem para óbito estão diretamente ligados ao manejo clínico.

\section{Caracterização da Área de Estudo}

Pirapora está localizada à margem direita do rio São Francisco na Mesorregião Norte de Minas Gerais. O Município está posicionado nas Coordenadas Geográficas Latitude $17^{\circ}$ 21' 55" e Longitude 4456' 59" (Mapa 1).

Mapa 1: Localização Geográfica do Município de Pirapora-MG.

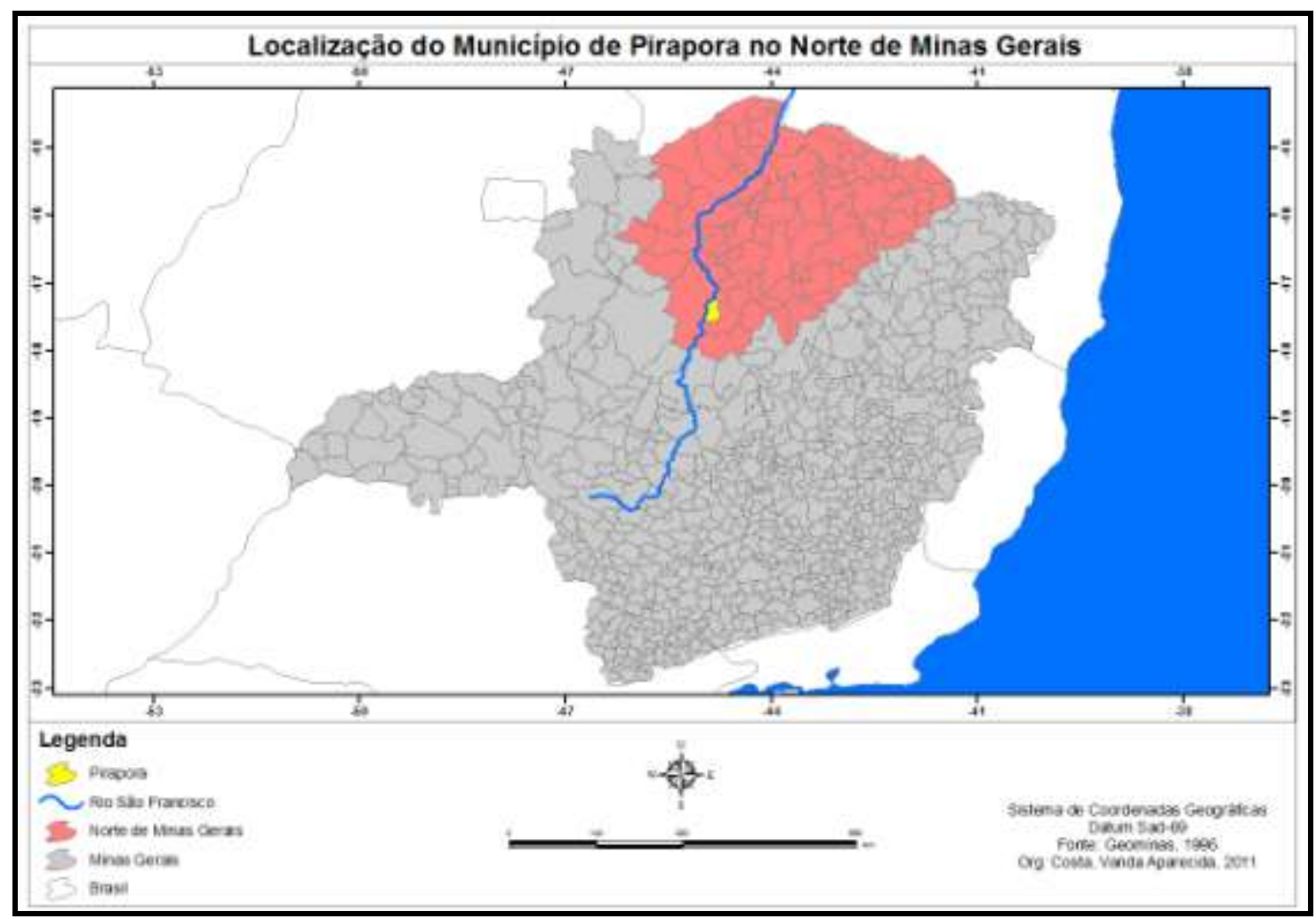

Org. Elab.: COSTA, V. A., 2011.

Fonte: GEOMINAS, 1996.

O Município de Pirapora - MG ocupa uma extensão territorial de $550 \mathrm{~km}^{2}$, contendo um total de população de 53.379 habitantes, sendo que a população urbana corresponde a 52.396 habitantes, ou seja, 98,2\% e a rural com apenas 983 habitantes (IBGE, 2010). De 


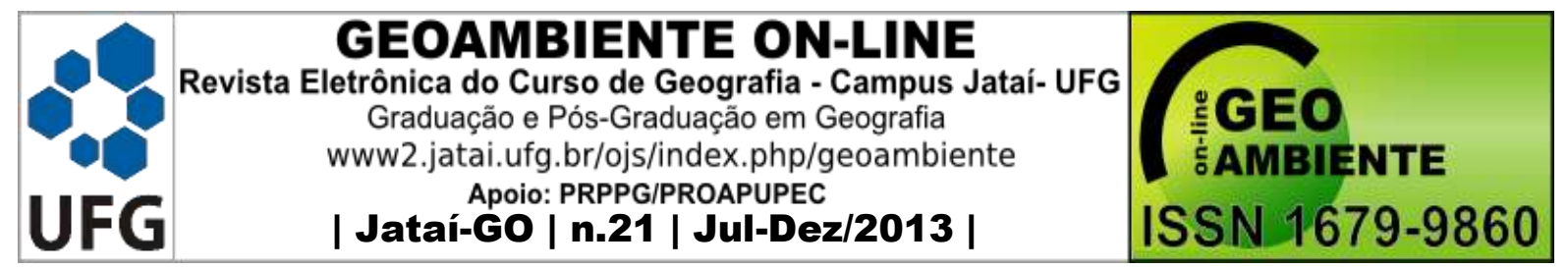

acordo com informações da Assembléia Legislativa de Minas Gerais, as médias anuais de temperatura no município oscilam entre $17^{\circ} \mathrm{C}$ e $30,7^{\circ} \mathrm{C}$, com média anual de $24,9^{\circ} \mathrm{C}$. A altitude máxima de Pirapora é registrada em local da Serra do Repartimento a 745 m, enquanto que o centro da sede está a 472 m, nível mínimo do município.

As precipitações variam de 900 a 1300 mm e com distribuição bastante irregular. Cerca de $80 \%$ das chuvas concentram-se no período de novembro a março, ocorrendo a estação seca no período de abril a outubro.

O crescimento demográfico da cidade está associado ao processo de industrialização da cidade, urbanização, êxodo rural, dentre outros. A mecanização no campo, expulsa os pequenos trabalhadores rurais que, na maioria das vezes não dispõem de recursos financeiros suficiente para a implementação de mecanismo moderno no campo. Diante disso, esses agricultores são expulsos da terra e migram para os centros urbanos a procura de emprego e melhores condições de vida.

É importante esclarecer que a cidade de Pirapora, teve sua origem nos migrantes, campo e cidade e de outras regiões do país, sobretudo do Nordeste. Consideramos que o crescimento demográfico foi possibilitado pelos deslocamentos humanos, possuindo implicações consideráveis para o desenvolvimento econômico. Com o aumento da população, ativou o comércio, a agricultura transformando-a num centro do sistema econômico e social.

O crescimento demográfico cria outros eventos econômicos e geográficos. A cidade de Pirapora tornou-se um centro polarizador no plano micro-regional. Núcleo urbano de atração de população de outros espaços, afligidos pelas adversidades climáticas ou devido às impossibilidades de se instalarem no campo, devido o domínio das grandes propriedades de terra. No entanto, foram esses fluxos constantes de deslocamentos que deram consistência ao espaço, aos lugares de trabalho na cidade e suas dinâmicas.

Os planos de modernização iniciados na segunda metade do século XX influenciam e cadenciam movimentos e feições geo-espaciais. O espaço, os lugares de vida na cidade, ganham novas dinâmicas, sobretudo de cunho produtivo via SUDENE (Superintendência do Desenvolvimento do Nordeste). Isso devido aos intuitos de modernização do espaço regional, como incentivos fiscais e financeiros. Nesse contexto, a cidade de Pirapora-MG se consolida como um cenário de investimento no setor industrial (RODRIGUES, 2000).

A atuação do Estado por meio da SUDENE na região Norte de Minas Gerais, sobretudo em algumas cidades isoladas, dentre elas, destacamos Pirapora-MG, aconteceu 


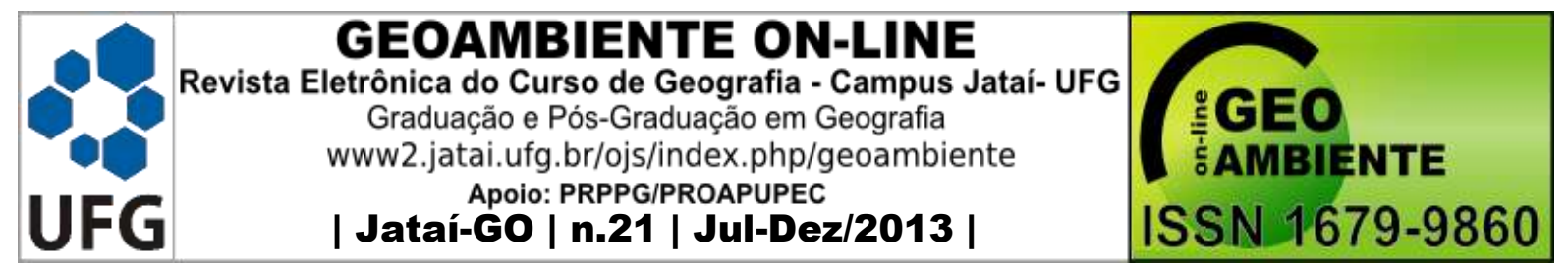

tendo como base a ordem inversa das coisas, "onde, conseqüentemente, o efeito é considerado causa, onde o fim se torna meio e o meio o fim" (LEFEBVRE, 1999, p. 97).

O relativo "atraso" econômico, pauta dos discursos desenvolvimentistas, era a causa dos problemas sociais dessa região e não o efeito de uma sociedade baseada na "opressão" econômica e social. Este efeito inverso pode ser compreendido em princípio, pelos intuitos que os projetos de inserção socioeconômica tinham para a região. As políticas públicas estavam voltadas para a melhoria das estruturas sociais e econômicas. Entretanto o que deveria ser um elemento de integração e coesão espacial gerou novos conflitos e, sobretudo cadenciou novos fluxos migratórios.

Com a expansão da indústria aliada à urbanização e especulação fundiária, gera-se por um lado, a escassez de terra em oferta e, por outro, aumentam o preço do solo, permitindo o aumento gradativo da renda via o valor de troca. Essa prática interfere na localização e no uso da terra dentro da cidade e, diacronicamente a cidade expande o seu tecido sobre os espaços adjacentes com menor valor agregado (CORRÊA, 1995). A construção de espaços inadequados à sobrevivência humana favorece muitas das vezes o criadouro do mosquito da dengue na cidade. E bom ressaltar também que na cidade de Pirapora encontram-se muitos terrenos baldios e casas abandonadas que com o período das chuvas contribui para o aumento e proliferação do mosquito da dengue.

\section{Resultados/Discussão dos dados obtidos}

Neste tópico, serão mensurados os principais casos de dengue na cidade de Pirapora, assim como o fator propulsor destes casos. Para isso, selecionaram-se como análise a média de umidade relativa na cidade de Pirapora nos anos de 2010 e 2011 com as notificações de dengue ocorridas neste mesmo período.

Um dos principais fatores que determinam a sobrevivência e a reprodução do vetor da dengue é a precipitação, que tem mostrado uma relação direta com o número de casos da doença. Neste sentido, a disseminação da dengue na cidade de Pirapora acontece principalmente no verão, sendo os meses de dezembro à fevereiro os mais críticos, pois, são nestes períodos que são registrados as maiores índices de chuva (gráfico 1), as mais elevadas taxas de umidade relativa do ar (gráfico 2) e de temperatura (gráfico 3).

Segundo Silva et al. (2007), a reprodução da dengue não ocorre nos primeiros meses que ocorre a precipitação. Desta maneira, pode-se analisar que a dengue pode ocorrer tanto no 


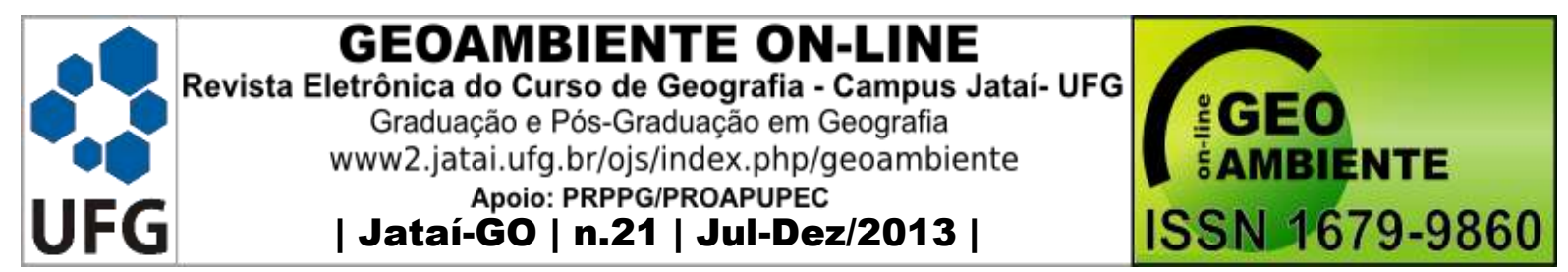

período chuvoso como pode acontecer no fim deste mesmo período, desde que alguns fatores climáticos como umidade e temperatura mantenham-se favoráveis à sobrevivência do vetor.

Gráfico 1: Precipitação Mensal em Pirapora-MG, anos de 2010 e 2011.

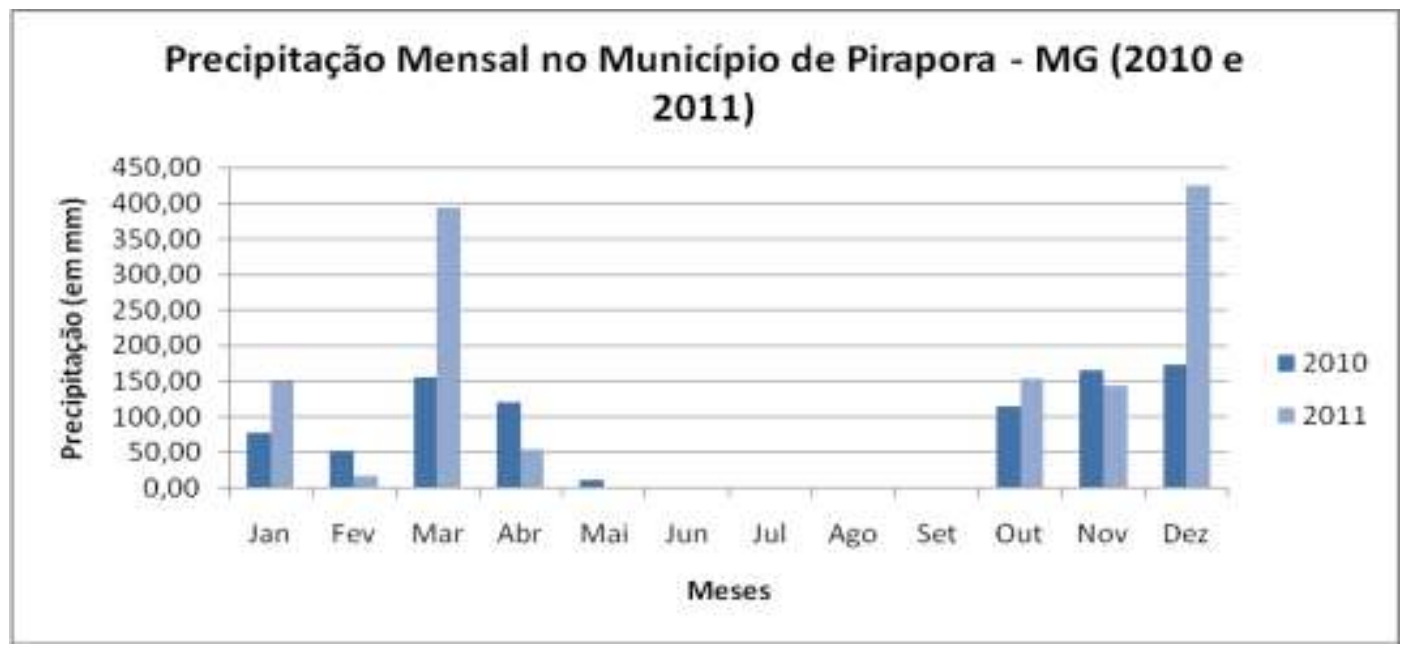

Fonte: INMET, 2012.

Org. Elab.: SILVA, J. P. G., 2012.

Gráfico 2: Média da Umidade Relativa Mensal no Município de Pirapora/MG: anos de 2010 à 2011.

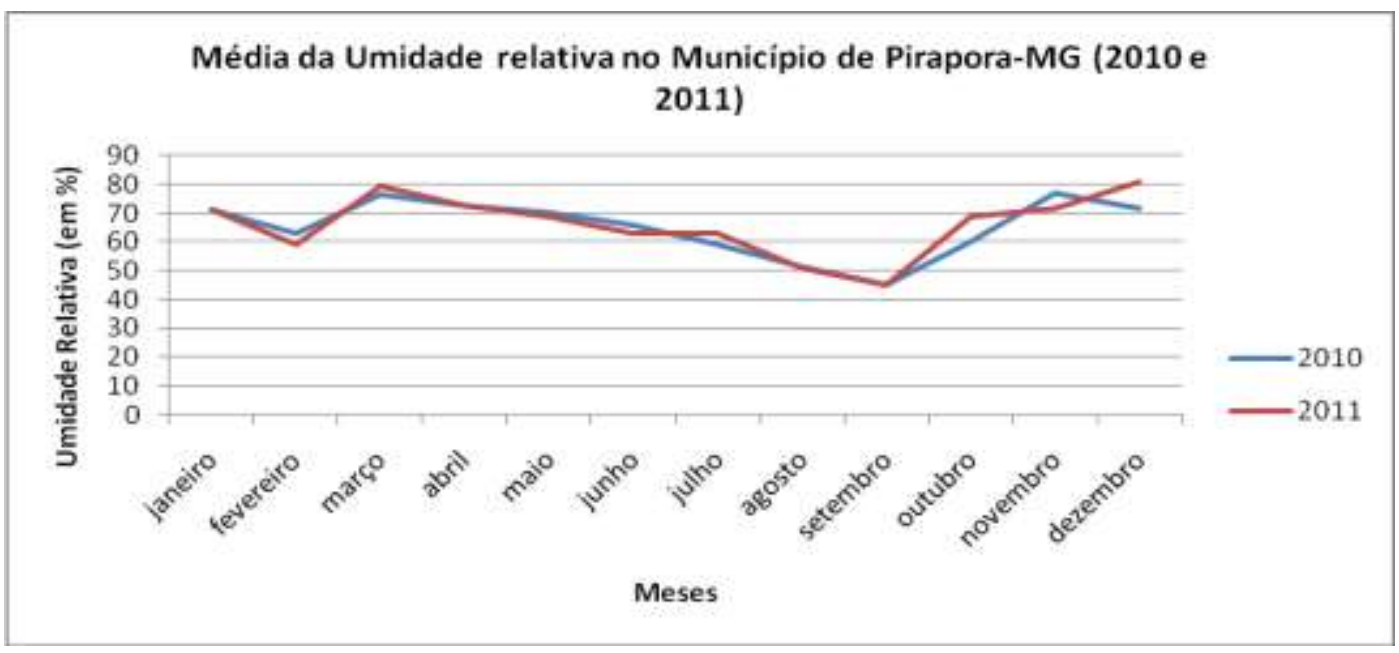

Fonte: INMET, 2012.

Org. Elab.: SILVA, J. P. G., 2012. 


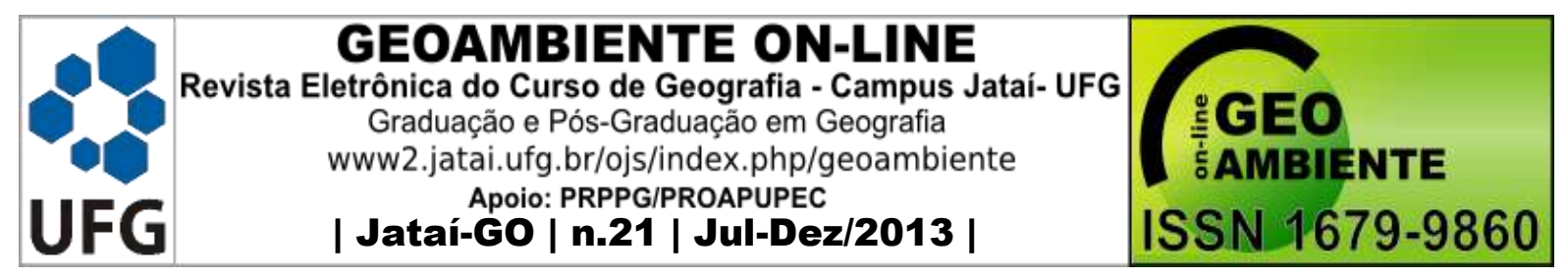

Gráfico 3: Temperatura Compensada Média no Município de Pirapora, nos anos de 2010 e 2011.

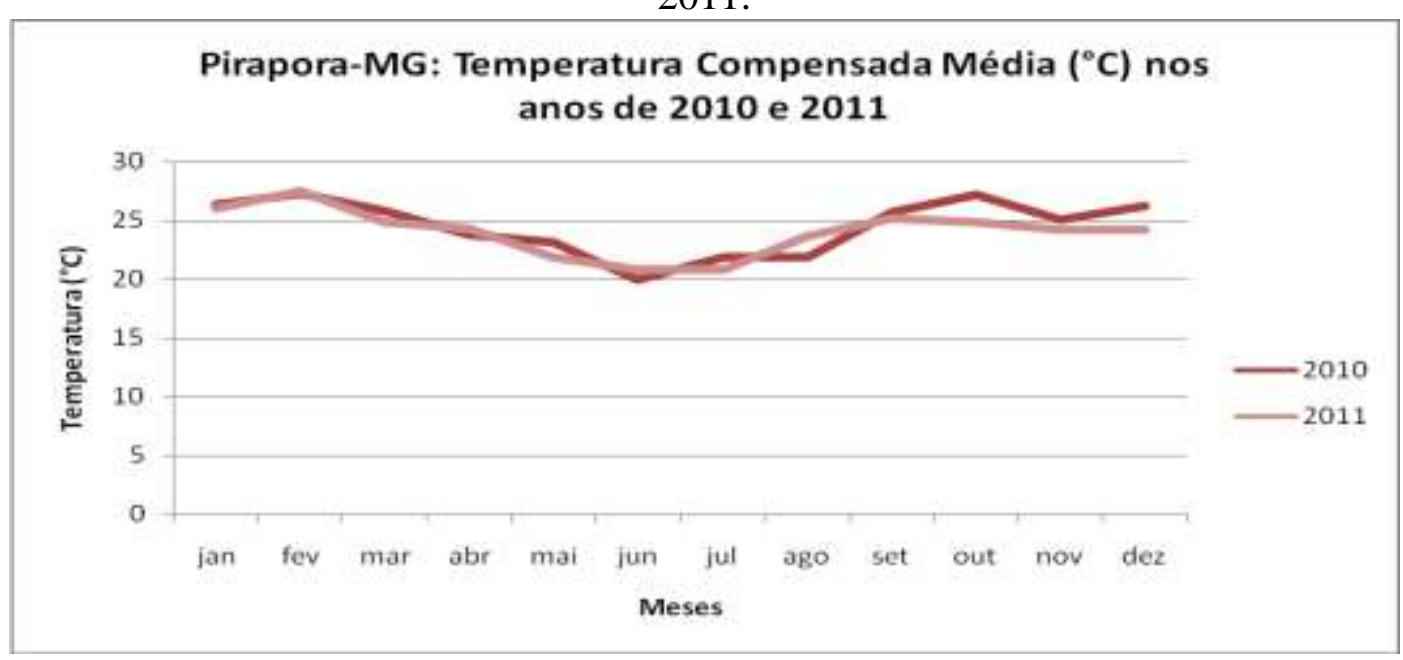

Fonte: INMET, 2012.

Org. Elab.: SILVA, J. P. G., 2012.

Ainda de acordo com o autor, no que tange a umidade relativa do ar o Aedes aegypti encontra grande potencialidade de desenvolvimento quando a mesma apresenta-se na faixa entre $70 \%$ a $100 \%$; essas condições serão satisfatórias para o desenvolvimento de todas as fases que compreendem o ciclo do mosquito Aedes aegypti.

A partir da análise dos dados apresentados no gráfico 2, é possível observar que os índices da taxa relativa de umidade do ar na cidade Pirapora sofrem variações relativamente pequenas no decorrer dos meses do ano. Conforme se observa no Gráfico 2, Pirapora permaneceu na média de 75 a 70\% de umidade relativa do ar no decorrer dos anos de 2010 a 2011, sofrendo poucas variações no decorrer do período estudado.

A temperatura é um dos principais fatores ambientais que influenciam direta e indiretamente os insetos, seja no seu desenvolvimento seja na alimentação. O conhecimento sobre a temperatura e seus efeitos no ciclo de vida é muito importante. Esse conhecimento, quando destinado ao Aedes aegypti, permite determinar épocas propicias à ocorrência da maioria dos casos e, assim, colabora na tomadas de decisões de controle do mosquito.

De acordo com Santos (2003) apud Cavalcante et al. (2007), a temperatura influencia o desenvolvimento do ciclo do mosquito, que vai de 5 a 7 dias desde que ocorram condições favoráveis de temperatura entre 25 e $29^{\circ} \mathrm{C}$; abaixo dessas temperaturas, o tempo de desenvolvimento fica mais demorado, e em temperatura inferior a $12^{\circ} \mathrm{C}$, há impedimento da larva transformar-se em pupa. 


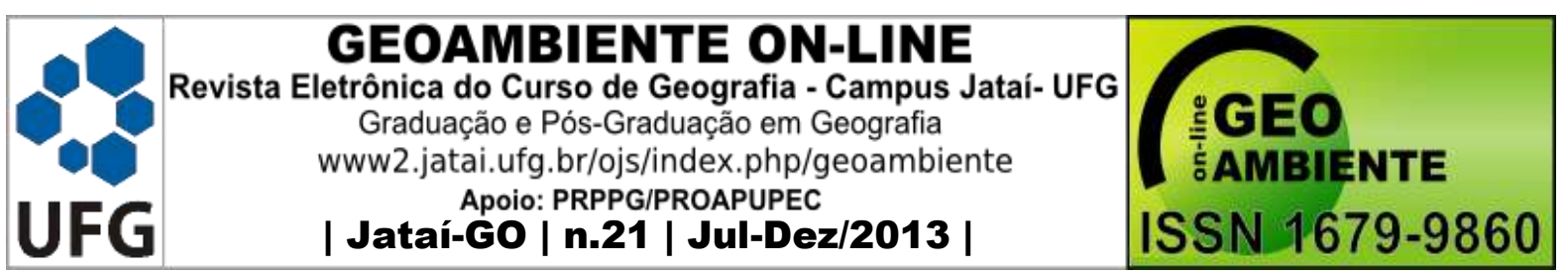

Sendo assim, analisando-se os dados contidos no gráfico 3, é possível concluir que o município de Pirapora-MG apresenta condições de temperatura totalmente favoráveis à sobrevivência e reprodução do vetor da dengue ${ }^{1}$. Ao longo dos anos de 2010 e 2011 a temperatura média sempre oscilou entre médias de 23 e 28 graus centígrados apresentando pequena variação entre os meses mais quentes e mais frios do ano.

O Gráfico 4 faz um relação entre a variação da incidência da dengue e os dados de precipitação no Município de Pirapora (MG). No ano de 2010 foram notificados 2.366 casos de dengue, caindo em 2011 para 203 casos notificados. A análise do gráfico permite perceber claramente a relação existente entre as chuvas e a ocorrência da dengue em Pirapora-MG.

A tabela 2 demonstra que ocorreu uma queda significativa no total de notificações da dengue em Pirapora no ano de 2010 se comparado ao ano de 2011. Pode-se verificar que em 2011, houve meses em que não foram notificados casos de dengue. Vale salientar, que os meses sem casos coincidem justamente com os meses de "seca" na região do Norte de Minas.

Gráfico 4: Relação entre Precipitação mensal e Notificações de casos de dengue no município de Pirapora-MG em 2010 e 2011.

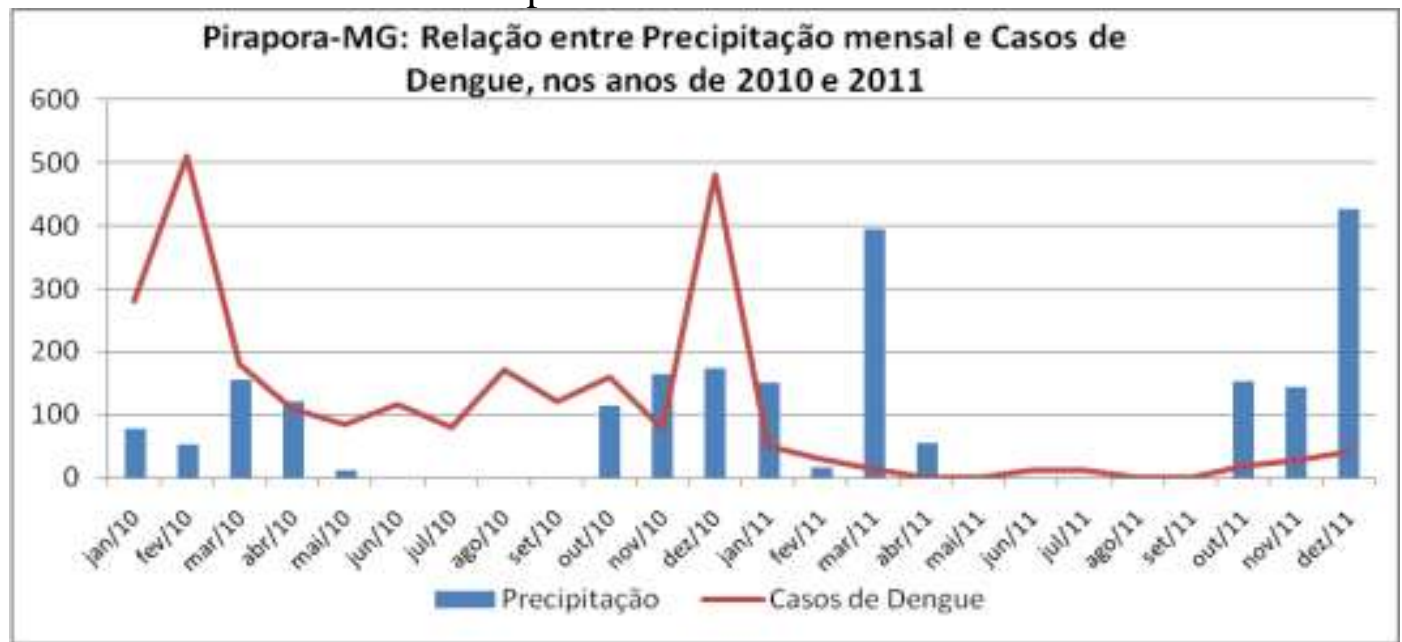

Fonte: SIAB; INMET, 2012.

Org. Elab.: SILVA, J. P. G., 2012.

\footnotetext{
${ }^{1}$ De acordo com Bessera et al. (2006), a temperatura favorável para o desenvolvimento do vetor da dengue está entre $21^{\circ} \mathrm{C}$ e $29^{\circ} \mathrm{C}$; entre $29^{\circ} \mathrm{C}$ a $32^{\circ} \mathrm{C}$ oferece-lhe potencialidade máxima ao desenvolvimento; e na faixa de $32^{\circ} \mathrm{C}$ a $34^{\circ} \mathrm{C}$ haverá um declínio no potencial máximo de desenvolvimento do vetor.
} 


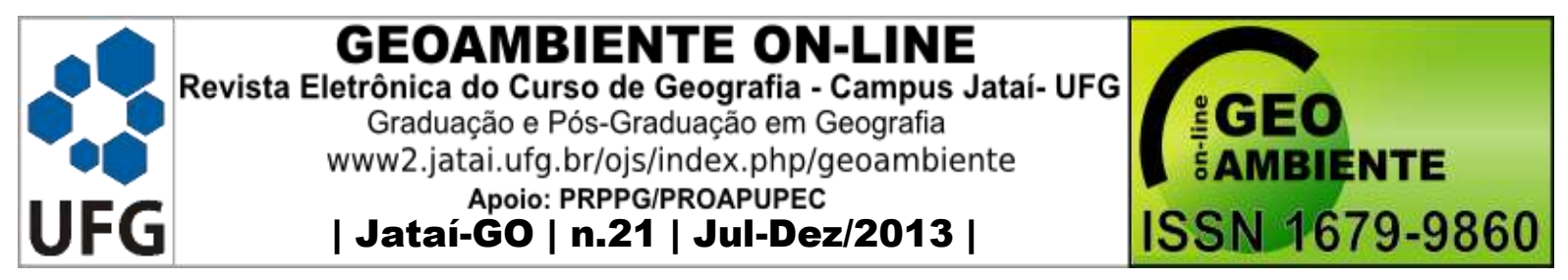

Tabela 2: Notificação de Casos de Dengue em Pirapora (MG) no Período 2010-2011.

\begin{tabular}{c|c|c|c}
\hline \multicolumn{3}{c}{ Notificação de Dengue em Pirapora - MG, em 2010 e } \\
\hline Meses & $\mathbf{2 0 1 0}$ & $\mathbf{2 0 1 1}$ & $\begin{array}{c}\text { Variação (2011 em } \\
\text { relação à 2010, em \%) }\end{array}$ \\
\hline janeiro & 280 & 50 & -460 \\
\hline fevereiro & 510 & 30 & -1.600 \\
\hline março & 180 & 13 & -1.285 \\
\hline abril & 110 & 0 & $* * *$ \\
\hline maio & 84 & 0 & $* * *$ \\
\hline junho & 115 & 12 & -858 \\
\hline julho & 80 & 12 & -567 \\
\hline agosto & 170 & 0 & $* * *$ \\
\hline setembro & 120 & 0 & $* * *$ \\
\hline outubro & 160 & 18 & -789 \\
\hline novembro & 77 & 28 & -175 \\
\hline dezembro & 480 & 40 & -1.100 \\
\hline TOTAL & 2366 & 203 & -1.066 \\
\hline Fonte: SIA & 2012. & &
\end{tabular}

Fonte: SIAB, 2012.

Org.: COSTA, V. A., 2012.

Elab.: SILVA, J. P. G., 2012.

Esta queda nos casos da dengue na cidade acompanhou uma tendência nacional, e foi resultado de diversos fatores, dentre eles, a intensificação do trabalho de prevenção/educação e aperfeiçoamento do atendimento médico à população, conforme menciona o Diretor da Regional de Saúde de Pirapora, Carlos Augusto de Lima: “Apesar de o município ter um alto índice de infestação do Aedes Aegypti, mosquito transmissor da dengue, o número de casos de dengue está sob controle, as ações de mobilização e educação em saúde foram intensificadas" (MINAS GERAIS, 2012).

Pode-se atribuir a redução de notificações ao trabalho de ponta que é feito pelos mobilizadores e educadores em saúde e pelos agentes comunitários do município, visto que por meio desses profissionais, a população recebe permanentemente orientações quanto aos cuidados para evitar a formação de focos do mosquito.

No Município de Pirapora são desenvolvidas diversas ações de combate à dengue mobilizadas pela Secretaria de Estado da Saúde. Os parceiros do município envolvidos estão orientando a população a fazer uma limpeza geral em seus quintais. Segundo a secretária municipal de Saúde, as campanhas de 2010 e 2011 foram alicerçadas nas escolas, envolvendo toda a comunidade em seu entorno: "Contou-se com a participação de 11 escolas municipais, 


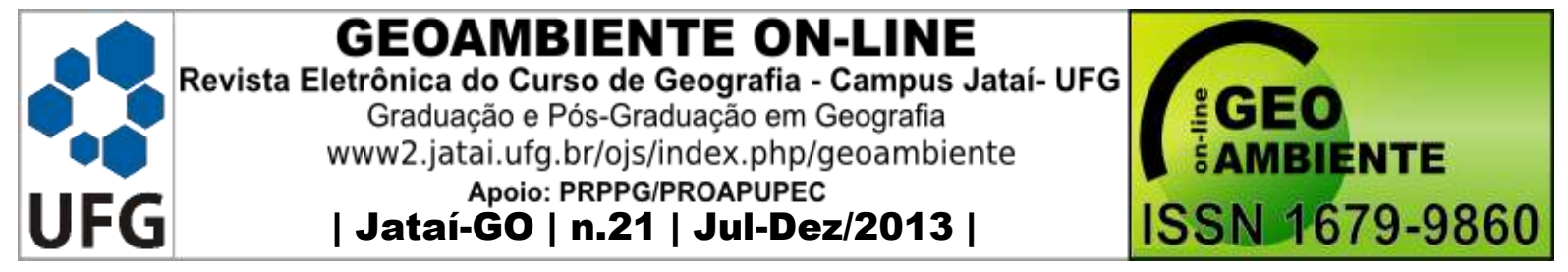

oito escolas estaduais e três creches, que foram divididas em dois grupos e o Dengue Móvel está percorrendo as escolas para recolher o material coletado junto à comunidade".

Outro fator que pode estar relacionado à redução do número de casos de Dengue no município e no país como um todo nos últimos anos, é a imunização natural da população ao vírus circulante em função da exposição do sistema imunológico dos indivíduos ao longo do tempo a uma determinada variação do vírus.

\section{Considerações Finais}

Baseado nos dados históricos de casos de dengue no município, bem como no comportamento dos elementos climáticos locais, percebe-se claramente a relação estabelecida entre os fatores ambientais naturais e a incidência de casos da dengue no estado de Minas Gerais, e mais especificadamente no Município de Pirapora.

Dessa forma, o número de casos da doença e a incidência do mosquito Aedes Aegypti estão diretamente relacionados aos índices pluviométricos do município. Os dados de temperatura e umidade permitiram concluir que o vetor teve condições ideais para o seu desenvolvimento no município de Pirapora-MG no período analisado.

Percebe-se que o Município de Pirapora acompanha a tendência nacional, que é a diminuição do número de casos de dengue desde a epidemia de 2010. Essa diminuição dos casos pode estar relacionada à diversos fatores como: detecção precoce da doença, a correta classificação de risco, a ampliação da assistência pela rede de atenção, bem como, ao ciclo de imunização da população em relação ao vírus circulante.

Por fim, a pesquisa demonstrou que existe grande influência dos fatores climáticos para a manifestação do mosquito Aedes aegypti e na ocorrência da dengue na área de estudo. Em um município com características naturais tão propícias ao desenvolvimento do vetor como Pirapora-MG, estas informações deveriam ser utilizadas como base para a elaboração de programas de controle e prevenção à doença.

\section{Referências}

BESSERA, E. B; JUNIOR, F. P. C; SANTOS, T. S.; FERNANDES, C. R. M. Biologia e exigências térmicas de Aedes aegypti (L.) (Diptera: culicidae) provenientes de quatro regiões bioclimáticas da Paraíba. Revista Neotropical Entomology. v. 35, n.6, p. 853- 860. 2006. 


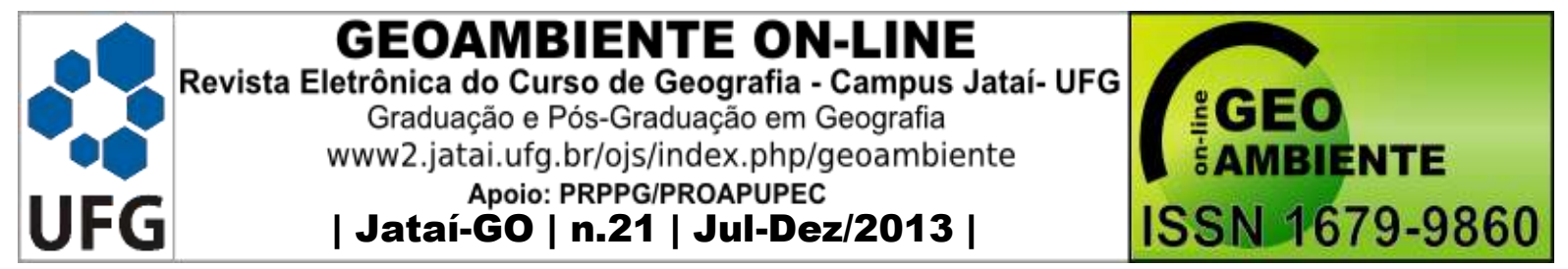

BRASIL, Ministério da Sáude. Boletim - Diminuem casos graves e mortes por dengue no país. Disponívelem:<http://portalsaude.saude.gov.br/portalsaude/noticia/8308/162/diminuemcasos-graves-e--mortes-por-dengue-no-pais.html> Acesso em 05 dez. 2012.

BRASIL. Ministério da saúde. Cartilha Dengue. Disponível em: <http://portal.saude.gov.br/portal/arquivos/flash/cartilha_dengue.html> Acesso em: 10 nov. 2012.

BRASIL. Ministério da saúde. DATASUS. SIAB - Sistema de Informação da Atenção Básica. Disponível em: < http://www2.datasus.gov.br/SIAB/index.php?area=0201> Acesso em 05 dez. 2012.

BRASIL. Ministério da saúde. Secretaria de Vigilância em Saúde. Departamento de Vigilância Epidemiológica. Diretrizes Nacionais Para a Prevenção e Controle de Epidemias de Dengue. Brasília: Ministério da Saúde, 2009. 160 p.

BRASIL. Ministério da Saúde. Secretaria de Vigilância em Saúde. Informe epidemiológico da dengue. Análise de situação e tendências - 2010. Secretaria de Estado de Saúde (SES-MG). Acesso em 23 nov. 2012.

CAVAlCANTE, K. R. L.; PORTO, V. T.; TAUIL, P. L. Avaliação dos conhecimentos, atitudes, e práticas em relação à prevenção de dengue na população de São Sebastião - DF. Brasil, 2006. Revista Ciências Saúde. v. 18, n. 2, p. 141-146. 2007.

INSTITUTO BRASILEIRO DE GEOGRAFIA E ESTATÍSTICA. Pesquisa Nacional de Amostragem de Domicílios: PNAD. Rio de Janeiro: IBGE, 2009. Disponível em: <http://www.ibge.gov.br/home/estatistica/populacao/trabalhoerendimento/pnad2009/> Acesso em 09 nov. 2012.

INSTITUTO NACIONAL DE METEOROLOGIA. BDMEP - Banco de Dados Meteorólogicos para Ensino e Pesquisa. Estação 83483: Pirapora/MG. Disponível em: < http://www.inmet.gov.br/portal/index.php?r=bdmep/bdmep> Acesso em: 19 nov. 2012.

LEFEBVRE, H. A Revolução urbana. Tradução de Sergio Martins. Belo Horizonte: editora da UFMG: 1999.

MENDONÇA, F., DANNI OLIVEIRA, I, F. Climatologia: Noções Básicas e Climas do Brasil. São Paulo: oficina de texto, 2007.

MINAS GERAIS. Agência Minas. Guerra contra a dengue em Pirapora. Disponível em: <http://www.saude.mg.gov.br/noticias_e_eventos/guerra-contra-a-dengue-em-pirapora-1/> Acesso em: 05 dez. 2012. 


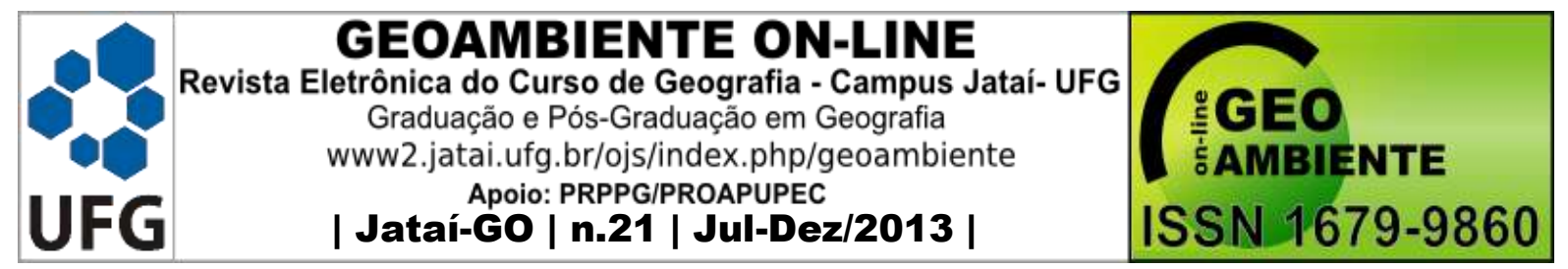

MINAS GERAIS. Agência Minas. Saúde reúne 30 municípios mineiros para aprimorar o combate à dengue.

Disponível

em:

<http://www.agenciaminas.mg.gov.br/multimidia/galerias/saude-reune-30-municipiosmineiros-para-aprimorar-o-combate-a-dengue/> Acesso em: 05 dez. 2012.

MINAS GERAIS. Assembléia Legislativa. Municípios de Minas Gerais. Disponível em: < http://www.almg.gov.br/consulte/info_sobre_minas/index.html?aba=js_tabMunicipios\&sltMu ni=512> Acesso em 10 dez. 2012.

MINAS GERAIS. Secretaria de estado da Sáude. Informe epidemiológico da Dengue em Minas Gerais (Nov. 2012). Disponível em: $<$ http://www.saude.mg.gov.br/publicacoes/estatistica-e-informacao-emsaude/boletimsemanaldengue/novembro/Informe\%20epidemiologico_dengue\%20\%2029\%20 11\%2012\%20\%282\%29.pdf> Acesso em: 05 dez. 2012.

MOURA, G. G., MENDES, P. C., PEDROSO, L. B., Ocorrência e distribuição espacial Da dengue no Triângulo Mineiro e Alto Paranaíba. Caderno Prudentino de Geografia. Presidente Prudente, $\quad$ v. $2, \quad$ n.34, 2012. Disponível em: < http://revista.fct.unesp.br/index.php/cpg/article/view/1952> Acesso em: 20 dez. 2013.

OLIVEIRA, E. S., AMARAL, L. P. Estudo da relação dos fatores climáticos e casos de dengue no município de Assis Chateaubriand, Paraná. Revista Engenharia Ambiental Espírito Santo do Pinhal, v. 8, n. 2, p. 171-181, abr. /jun. 2011.

PEDROSO, L. B., MOURA, G. G. Distribuição Espacial da Dengue no Município de Ituiutaba/MG, 2009-2010. Revista Hygeia. V.8, n.15 (2012). Disponível em: < http://www.seer.ufu.br/index.php/hygeia/article/view/17297> Acesso em: 20 dez. 2013.

PIRAPORA. PREFEITURA MUNICIPAL. Dados Físicos e Econômicos. Disponível em: $<$ http://www.pmppirapora.com.br/index.php?page=paginas\&idPagina=14> Acesso em: 05 dez. 2012.

RODRIGUES, Luciene. A Formação econômica do norte de minas e o período recente. Formação econômica e social do norte de minas. Montes Claros. UNIMONTES, 2000, p.105 $-170$.

SILVA, S. J.; MARIANO, Z. F.; SCOPEL, I. Influencia do clima urbano na proliferação do mosquito Aedes aegypti em Jataí (GO) na perspectiva da geografia médica. Revista Hygeia, v. 2, n.5, p.33-49, 2007. 


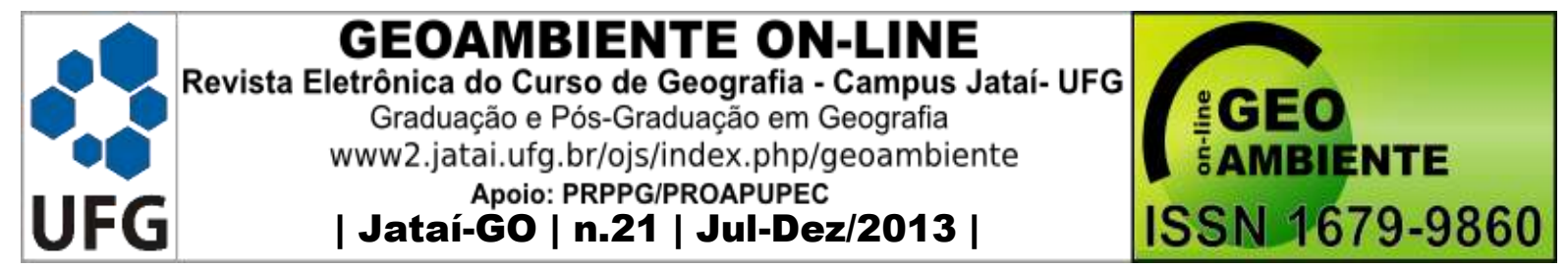

SILVA, S. J.; MARIANO, Z. F.; SCOPEL, I. A dengue no Brasil e as políticas de combate ao Aedes aegypti: da tentativa de erradicação ás políticas de controle. Revista Hygeia, v.3, n.6, p.163-175, 2008.

SOUZA, R. R. Os casos de dengue na cidade de Barra do Garças - MT. Ateliê Geográfico, v.4, n.4, 2010. Disponível em:< http://www.revistas.ufg.br/index.php/atelie/article/view/16670> Acesso em: 20 dez. 2013. TEIXEIRA, M. da G.; BARRETO, M. L.; GUERRA, Z. Epidemiologia e medidas de prevenção do dengue. Salvador, Instituto de Saúde Coletiva/UFBA, 1999, v. 8, n. 4, p. 5-33. 